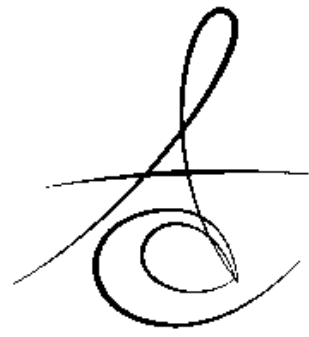

Makale Kodu/Article code: 1643

Makale Gönderilme tarihi: 22.04.2014

Kabul Tarihi: 10.10 .2014

\section{KIRIK DİŞ SENDROMU VE AYIRICI TEŞHİSİNDE KONİK IŞINLI BİLGISSAYARLI TOMOGRAFININN ROLÜ: OLGU SUNUMU}

\section{CRACKED TOOTH SYNDROME AND THE ROLE OF CONE-BEAM COMPUTED TOMOGRAPHY IN THE DIFFERENTIAL DIAGNOSIS: A CASE REPORT}

\author{
Yrd. Doç. Dr. Cüneyt Asım ARAL*
}

Yrd. Doç. Dr. Evren OK ${ }^{* *}$

\section{ÖZET}

Dental pratikte sıklıkla karşılaşılan Kırık diş sendromu, oluşturduğu şiddetli ağrı semptomlarını gidermek amacıyla hızı teşhis ve tedavi yaklaşımı gerektiren bir problemdir. Bu olgu sunumunda; teşhisi ve tedavisi gecikmiş bir vaka sunulmaktadır.

: Herhangi bir sağlık problemi olmayan 40 yaşındaki bir erkek hasta kliniğimize başvurdu. Hasta hikâyesinde özellikle çiğneme esnasında, ayrıca sıcak ve soğuk yiyecekler sırasında sağ üst dişlerinde elektrik çarpması tarzında ağrılar hissettiğini ve bu şikâyetlerine bir yıldır teşhis konulamadığını belirtti. Hastanın intraoral muayenesinde; dişlerde generalize atrizyon, abrazyon ve dişeti çekilmesi bulgularına rastlandı. Gözle muayene, transillüminasyon ve boyama yöntemleriyle maksiller 1 . ve 2 . premolarlar ve 1. molar dişlerin palatinal yüzeylerinde çatlaklar izlendi. Konik ışınlı bilgisayarlı tomografi incelemesinde maksiller 2. premolar dişte görülen çatlağın pulpaya ulaştığı izlendi.

Isırtma testinde hassasiyet gözlenen ve hiperemik olan maksiller 2. premolar dişe kanal tedavisi uygulandı. Kontrol seanslarında hastamızın şikâyetlerinin tamamen kaybolduğu gözlendi. Çatlakların etyolojisinde rol oynayan bruksizmin tedavisi için koruyucu plak uygulaması önerildi. Hastamızın anksiyete bozukluğu psikiyatri uzmanına konsülte edildi.

Anahtar Kelimeler: Kırık diş sendromu, Konik Işınlı Bilgisayarlı Tomografi, Dentin hassasiyeti, Bruksizm

\section{ABSTRACT}

Cracked tooth syndrome is a problem frequently encountered in dental practice and requires immediate diagnosis and treatment in order to eliminate the symptoms of severe pain. In this report; a case of delayed diagnosis and treatment is presented.

A 40-year-old male patient who had no health problem referred to our clinic. In his history, the patient complained about an electric shock-like pain in the right upper teeth especially during chewing, and also during eating cold and hot foods and also he stated that his complaints couldn't be diagnosed over a year. In intraoral examination; generalized attrition and abrasion, and gingival recessions of the teeth were detected. Cracks were observed on the palatal surface of maxillary first and second premolar, and first molar teeth, through visual inspection, transillumination, and staining methods. Examination of the Cone-beam Computed Tomography revealed that the crack of the maxillary fist premolar tooth reached the pulp.

Root canal treatment was performed to the maxillary fist premolar tooth which had hyperemia and sensitivity to bite test. In the control sessions, it was observed that the complaints of the patient disappeared completely. Usage of a mouth guard was recommended for the treatment of bruxism which is taught to play a role in the etiology of the cracked tooth syndrome. Anxiety disorder of the patient was consulted to a psychiatrist.

Key Words: Cracked tooth syndrome, Conebeam Computed Tomography, Dentine sensitivity, Bruxism

\footnotetext{
* Şifa Üniversitesi, Diş Hekimliği Fakültesi, Periodontoloji Anabilim Dalı

** Şifa Üniversitesi, Diş Hekimliği Fakültesi, Endodonti Anabilim Dalı
} 


\section{GİRIŞ}

Kırık diş sendromu terimi, 1964 yılında Cameron tarafından tanımlamıştır. ${ }^{1}$ Çatlak kusp sendromu, split diş sendromu veya yeşil dal kırığı isimleri ile de bilinmektedir. Kırık diş sendromu; mine ve dentini içeren ve pulpaya ulaşabilen fakat tamamlanmamış kırıklar ve oluşturdukları semptomları ifade eder. ${ }^{1}$ Kırık diş sendromu; kimyasal ajanlara, termal, osmotik veya mekanik uyaranlara cevaben oluşan kısa süreli ve keskin ağrı olarak belirti vermektedir. ${ }^{2}$ Semptomların şiddetli seyretmesi ve birçok farklı klinik rahatsızlık ile karışması, kırık diş sendromunun teşhisini kolaylaştıracak yeni metodların değerlendirilmesinin önemini artırmaktadır.

Konik ışınlı bilgisayarlı tomografi (KIBT), baş boyun bölgesindeki anatomik yapıların daha iyi görüntülenebilmesi ve konvansiyonel bilgisayarlı tomografinin dezavantajlarının ortadan kaldırılabilmesi için üretilen güncel bir tıbbi görüntüleme tekniğidir. ${ }^{3,4}$ $\mathrm{Bu}$ vakada; teşhisi ve dolayısıyla tedavisi gecikmiş bir kırık diş sendromunun semptomları, etyolojisi, teşhisi, ayırıcı tanısı, tedavisi ve prognozu tartışılmıştır. Ayrıca KIBT'nin görüntü çözünürlüğünün yüksek olması nedeniyle kırık diş sendromunun teşhisinde kullanılabileceği gösterilmiştir.

\section{OLGU SUNUMU}

Herhangi bir sağlık problemi olmayan ve sigara kullanmayan 40 yaşındaki bir erkek hasta, dişlerinde hassasiyet ve ağrı nedeniyle, bir dış merkezin yönlendirmesi sonucu Şifa Üniversitesi Diş Hekimliği Fakültesi Periodontoloji Kliniği'ne başvurdu. Hastamızın şikâyetlerinin bir seneden beri olduğu, fakat teşhis konulamadığı öğrenildi. Hastamız, özellikle çiğneme sırasında sağ üst çenesine ve başına vuran elektrik çarpması tarzında ağrılar hissettiğini ve benzer ağrıların sıcak ve soğuk yiyecekler sırasında da oluştuğunu bildirdi.

Hastamızın ekstraoral bulgularında; Massater kasın tonusunda artış ve ağız açma sırasında klicking sesi bulguları saptandı. Alınan hikâyede, hastamızın diş sıkma ve gıcırdatma alışkanlığı olduğu öğrenildi. İntraoral muayenede, dişlerin insizal ve okluzal yüzeylerinde bruksizme bağlı atrizyonlar izlendi. Dişlerin bukkal kole bölgelerinde, sert fırça ile hatalı fırçalamaya bağı aşınmalar ve Miller I dişeti çekilmeleri teşhis edildi (Resim 1 ve 2). Ayrıca maksiller sağ kanin diş bölgesinde fırça travmasına bağlı minör bir ülserasyon saptandı (Resim 2). Hava spreyi ve sond ile yapılan muayenede, sağ maksiller dişlerinin bukkal kole defektlerinin asemptomatik olduğu not edildi. Maksiller sağ premolar ve 1 . molar dişlerin palatinal yüzeylerinde çatlak hatları tespit edildi (Resim $3 A$ ve $3 B$ ). Çatlak hatları, povidon iyodür solüsyonu (Batticon ${ }^{\circledR}$, Adeka İlaç Sanayi, İstanbul, Türkiye) ve LED ışık kaynağı ile transillüminasyon yöntemleri ile doğrulandı (Resim 4 ve 5). Lastik ısırtma testinde, ağrının maksiller 2. premolar dişten kaynaklandığı ve maksiller 1. premolar dişin asemptomatik olduğu not edildi. Dış merkezde ağrının etiyolojisini saptamak amacıyla alınan KIBT'de yapılan incelemede, maksiller 2. premolar dişin palatinal yüzeyinde çatlak hattı saptandı ve çatlağın pulpaya kadar ulaştığı görüldü (Resim 6). İlgili dişte perküsyona karşı hafif şiddette hassasiyet izlendi. Hastamızın bilgilendirilmesinin ve onayının ardından maksiller 2. premolar dişe kanal tedavisi uygulandı. Takip eden kontrol seanslarında, hastamızın şikâyetlerinin tamamen kaybolduğu izlendi. Çatlakların etyolojisinde rol oynayan bruksizmin tedavisi için koruyucu plak uygulaması önerildi. Günlük yaşantısında anksiyetik olduğunu, gündüzleri istemli olarak dişlerini sıktığını ve geceleri eşinin fark etmesi ile diş gıcırdatma şikâyetlerinin olduğunu bildiren hastamızın durumu, yazılı olarak psikiyatri uzmanına konsülte edildi. Tıbbi konsültasyon sonucunda, Psikiyatri hekimi tarafından hastamıza anksiyolitik ilaç önerildi.

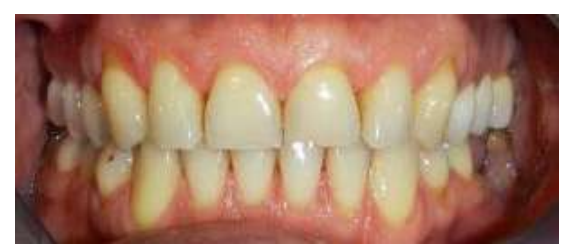

Resim 1. Ağız içi fotoğraf. Generalize atrizyon, abrazyon ve dişeti çekilmeleri izlenmekte.

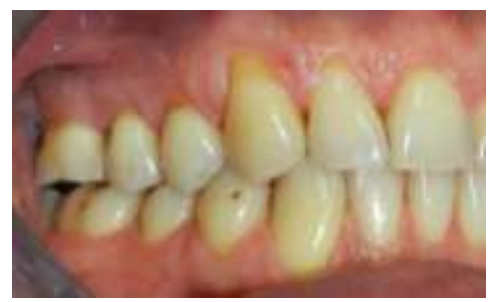

Resim 2. Hastamızın ağrısından şikâyetçi olduğu sağ maksiller bölgenin ağız içi fotoğrafı. Hatalı fırçalamaya bağlı maksiller sağ kanin ve lateral dişler arasındaki dişetinde fırça travmasına bağlı hafif ülserasyonlar izlenmekte.

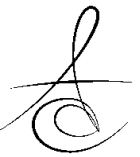




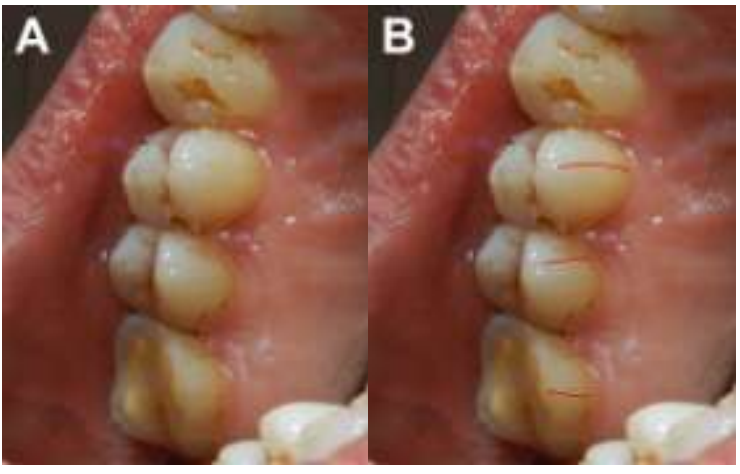

Resim 3. A) Maksiller 1. ve 2. premolarlar ve 1. molar dişlerin palatinal yüzeylerinin görüntüsü. B) Kırmızı çizgi ile palatinal yüzeylerdeki çatlakların belirtilmesi.

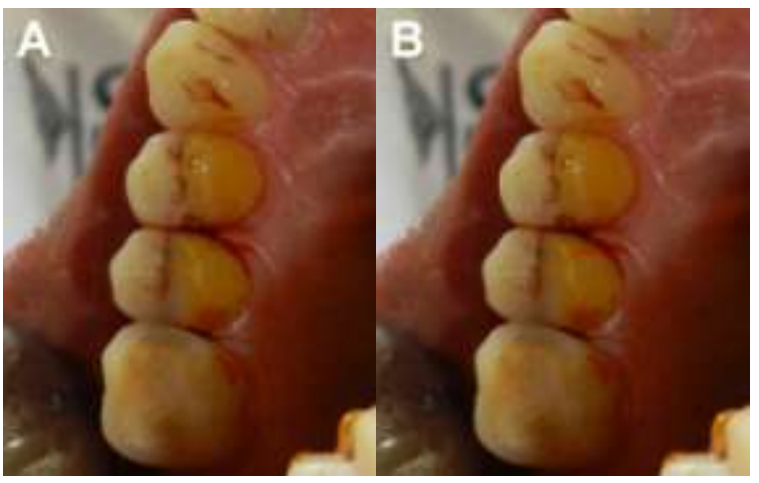

Resim 4. A) Boyama sonrası maksiller 1. ve 2. premolarlar ve 1. molar dişlerin palatinal yüzeylerinin görüntüsü. B) Kırmızı çizgi ile palatinal yüzeydeki çatlağın belirtilmesi.

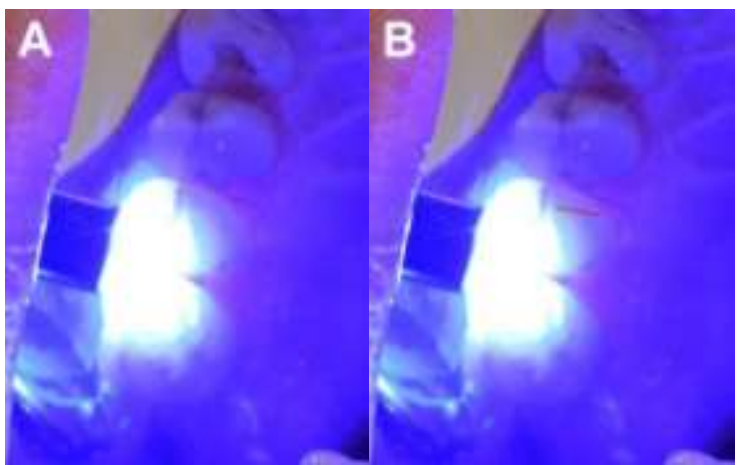

Resim 5. A) LED ışık kaynağı ile yapılan transillüminasyon sonrası maksiller 1 . ve 2 . premolarlar ve 1 . molar dişlerin palatinal yüzeylerinin görüntüsü. B) Kırmızı çizgi ile palatinal yüzeydeki çatlağın belirtilmesi.

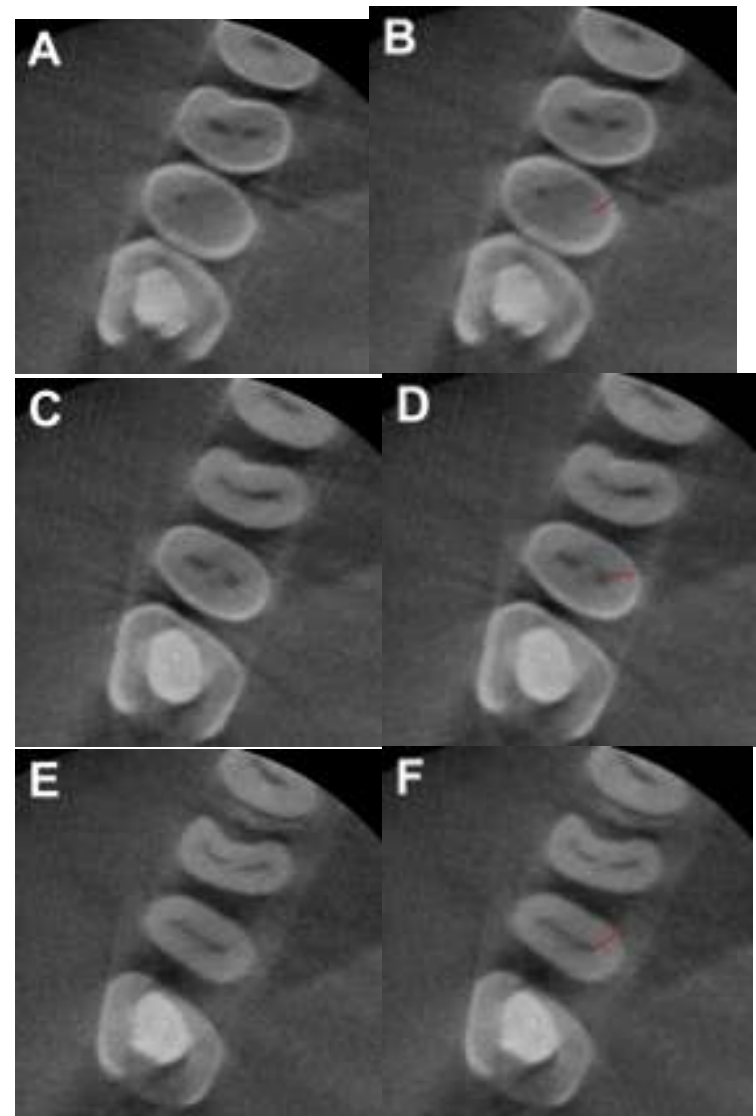

Resim 6. Maksiller 1. ve 2. premolarlar ve 1. molar dişlere ait farklı KIBT aksiyal kesitlerinin görüntüsü. $A, C$ ve $E$ ) Maksiller 2. premolar dişteki çatlağın pulpaya ulaştığı görülüyor. B, D ve F) Maksiller 2. premolar dişteki çatlağın kırmızı çizgi ile belirtilmesi.

\section{TARTIŞMA}

Kırık diş sendromuna bağlı semptomlar çok çeşitlilik gösterir. Hasta, özellikle ısırma sırasında şiddetli ağrı hissedebilir. Ayrıca sıcak ve soğukta sızlayıcı tarzda ağrılar eşlik edebilir. Bakteri ve bakteri ürünlerinin çatlak boyunca pulpaya ulaşması sonucu dişler hiperemik duruma geçebilir. ${ }^{5}$ Hiperemi tabloya eşlik ettiği zaman semptomlar daha da şiddetlenir.

Kırık diş sendromunun etyolojisinde en başta büyük restorasyonlar gelmektedir. ${ }^{6}$ Diş dokularının kaybına sebep olan çürükler, geniş veya yüksek yapılmış restorasyonlar, akut veya kronik (bruksizm gibi) travmalar kırık diş sendromunun gelişmesinde rol oynamaktadır. ${ }^{7}$ Dişlerde fizyolojik olmayan sıkma ve gıcırdatma olarak tanımlanan bruksizm, uyku sırasında

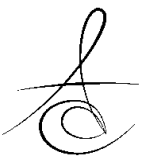


veya uyanıkken gerçekleşebilmektedir. ${ }^{8}$ Sunulan olguda, kırık diş sendromunun etyolojisinde bruksizm rol oynamaktadır. Literatürde ayrıca, derin okluzal oluklar gibi morfolojik faktörler, hatalı kavite preperas- yonu ve yanlış restoratif materyal seçiminin de tamamlanmamış çatlaklara sebep olabildiği vurgulanmıştır. ${ }^{2}$

Erken teşhis özellikle dental ağrılı durumlarda önem kazanmaktadır. Böylece tedavi geciktirilmeden yapılabilir ve hasta konforu artırılabilir. Kırık diş sendromunun teşhisi tecrübeli klinisyenler için bile zor sayılmaktadır. Çünkü semptomlar birçok hastalık ile karışabilmektedir. Kırık diş sendromunun teşhisinde ilk önce çatlağın varlığı kontrol edilmelidir. Bu amaçla; aydınlatma altında çıplak gözle muayene, sondla çatlak hattının hissedilmesi, LED ışık kaynağı ile transillüminasyon $^{9}$ ve diş yüzeyinin boyaması ${ }^{7}$ yöntemleri kulanılabilir. Kırık diş sendromunda plastik çubuk ile yapılan ısırtma testi sırasında tetiklenen ağrı, inter okluzal istirahat pozisyonuna geçildikten sonra azalarak kaybolmaktadır. Isı testleri ve vitalite kontrolü semptomların kaynaklandığı dişin teşhisinde önerilebilir. ${ }^{6}$ Kırık diş sendromlu diş, elektrikli pulpa testlerine genellikle normal yanıt vermektedir. ${ }^{10}$

Periapikal ve bite-wing radyograflar çatlak hattının ayırt edilmesinde yeterli değildir. Konvansiyonel radyograflara göre üç boyutlu görüntüleme avantajı sağlayan KIBT'nin, çatlak dişlerin teşhisinde faydalı bir yöntem olabileceği güncel vaka raporlarında gösterilmiştir. ${ }^{11}$ KIBT'nin, geleneksel bilgisayarlı tomografiye göre tarama süresinin kısa olması, hasta hareketine bağlı artefakt oluşumu olasılığını ve alınan radyasyon miktarını azaltmıştır. ${ }^{12}$ Düşük $\mathrm{mA}$ ve radyasyon dozu, diğer Bilgisayarlı Tomografi görüntüleme metotları ile maruz kalınandan önemli ölçüde düşüktür. ${ }^{13,14}$ Ayrıca en az distorsiyonla maksillofasiyal iskeletsel yapıların yüksek çözünürlükte görüntülerini sağlamadaki yeteneği, bu teknolojinin tercih sebebi yapmaktadır. ${ }^{15}$ Tüm bu avantajlarına rağmen, KIBT ile alınan radyasyon miktarının yüksekliği akıldan çıkarılmamalı ve yalnızca kapsamlı inceleme sonucu teşhiste zorlanılan vakalarda kullanılmasının faydalı olacağı unutulmamalıdır. ${ }^{11} \mathrm{Bu}$ vakada yapılan KIBT incelemesinde çatlak hattının izlenmesi, KIBT'nin kırık diş sendromunun teşhisinde kullanılabileceğini göstermektedir.

Kırık diş sendromunun ayırıcı tanısında, dentin hassasiyeti başta gelmektedir. ${ }^{16}$ Atrizyon, erozyon, abrazyon lezyonlarıyla ya da hatalı diş fırçalama sonucu dişeti çekilmesi sonucu dentin yüzeyi ağız ortamına açılabilir. Açıkta olan dentin yüzeyi, dentin tübüllerindeki sıvı hareketine bağlı olarak odontoblast ve uzantılarının veya pulpadaki dentin reseptörlerinin çeşitli etkenler tarafından uyarılmasına bağı olarak hassas olabilir. ${ }^{17,18} \mathrm{Bu}$ olguda, hastamızın kliniğimize yönlendirilmesinin asıl sebebi, ağrının sebebinin hatalı fırçalamaya bağlı görülen dişeti çekilmeleri ve kole defektlerinden kaynaklandığının düşünülmesiydi. Fakat yapılan muayene ile açıkta olan dentin ve sement yüzeyinin hassas olmadığı görülmüştür.

Tedavide en konservatif yaklaşım çatlağı içeren bir dolgu yapılmasıdır., ${ }^{6,19,20}$ Böylece stabilizasyon sağlanıp çatlağın hareketi en aza indirgenir. Daha ileri vakalarda dişin kronlanması düşünülebilir. ${ }^{21} \mathrm{Bu}$ sayede çatlak hattı kronun içerisinde bırakılarak dentin tübüllerindeki sıvı hareketi kısıtlanmış olur. Aynı zamanda çatlağın dış ortam ile ilişkisi tamamen kesilir. Pulpal hiperemi, dejenerasyon veya kök rezorpsiyonu varlığında kanal tedavisi gerekebilir. ${ }^{22}$ Kanal tedavisi sonrası vitalite ortadan kaldırılığı için semptomlar da ortadan kaldırımış olur. Fakat kanal tedavisi sonrası oluşan internal madde kaybının fraktür hattının ilerlemesine altyapı sağlayabileceği unutulmamalıdır. ${ }^{23}$ $\mathrm{Bu}$ tür riskler varlığında dişlerin ayrıca kronlanması düşünülebilir. İlgili dişin çekimi için acele edilmemelidir, çekim en son düşünülecek tedavi seçeneğidir.

Uzun dönem başarılı bir tedavi için, etyolojik faktörlerin tamamen ortadan kaldırıması gerekliliği unutulmamalıdır. Etyolojide maloklüzyon varsa ortodontik tedavi, prematür kontakt varsa okluzal uyumlama yapılmalıdır. Kırık diş sendromunun altında yatan etken bruksizm ise tedavi yaklaşımı multidisipliner olmalıdır. Bruksizmin etiyolojik faktörleri; morfolojik, santral ve psikolojik olmak üzere 3 gruba ayrılmaktadır. Dental okluzyonda ve çene yüz bölgesinin anatomisindeki bozukluklar morfolojik faktörleri oluşturmaktadır. ${ }^{8}$ Santral sinir sisteminde değişiklik oluşturan genetik faktörler ve nörokimyasallar da özellikle uykuda bruksizm oluşturmaktadır. ${ }^{24,25}$ Propranolol ve antidopaminerjik gibi bazı ilaçların kullanımına bağlı olarak sekonder bruksizm oluştuğu da gösterilmiştir. ${ }^{26}$ Dolayısıyla klinisyenler ilaca bağlı yan etkileri de mutlaka değerlendirmelidirler. Psikolojik stres, bruksizm etiyoloji teorileri arasında önemli bir yer tutmaktadır. Anksiyetik ve hiperaktif kişiliğe sahip bireylerin psikiyatrik durumu tıp hekimine konsülte edilebilir ve konsültasyon sonucu anti-stres ilaçlardan faydalanılabilir. ${ }^{27}$ Ayrıca, bruksizm alışkanlıklarını gidermek ve bruksizmin yıkıcı etkilerini 
ortadan kaldırmayı amaçlayan protetik tedavi yaklaŞımları düşünülebilir. ${ }^{28}$ Bruksizm, dental ve periodontal dokularda yıkıcı olabildiği gibi, temporamandibuler eklemleri de negatif yönde etkileyebilir. ${ }^{29} \mathrm{Bu}$ nedenle eklemlerde görülebilecek dejeneratif değişiklikler değerlendirilmeli ve gerekiyorsa tedavi edilmelidir.

Komplike olmayan yani kök yüzeyine uzanmayan çatlakların tedavisi kolay ve prognozu iyidir. ${ }^{6}$ Özellikle köke uzanan ve alveolar kemiğin marjinini aşan vertikal yöndeki çatlaklar, bakterilerin subgingival ortama ulaşmalarına, patolojik cep formasyonuna ve alveolar kemik yıkımına sebep olabilirler. İleri vakalarda prognoz kötüleşir ve dişin çekimi gerekebilir.

Literatürde yer alan diğer olgu sunumları değerlendirildiğinde, kırık diş senromunun teşhisinde KIBT'nin kullanıldığı sadece bir makale bulunmaktadır. ${ }^{11}$ Dolayısı ile makalemiz, literatürde yer alan bu makaleyi desteklemekte ve KIBT'nin teşhisteki başarısını vurgulamaktadır. Kırık diş sendromunun tedavisinde; çatlak hattının kompozit rezin ile restorasyonu, ${ }^{6}$ seramikler ile restorasyonu, ${ }^{30}$ amalgam dolgu ile restorasyonu, ${ }^{31}$ supra koronal splintleme, ${ }^{32}$ kök kanal tedavisi $^{33}$ ve çekim ${ }^{34}$ yaklaşımları literatürde bildirilmiştir. Sunulan vakamızın tedavisi amacıyla, hastamızın bilgilendirilmesinin ve onayının ardından ilgili dişe kanal tedavisi uygulanmış ve kontrol seanslarında, hastamızın şikâyetlerinin tamamen kaybolduğu izlenmiştir.

Klinisyenlerin bilgi düzeylerinin yeterli olmamasından dolayı Kırık diş sendromunun teşhis ve tedavisi gecikmektedir. Kırık dişe bağlı sendromlar şiddetlidir ve hastanın yaşam kalitesini etkilemektedir. Konservatif tedavi seçeneklerinin bulunmasına rağmen kırık diş sendromu teşhisi konulamayan vakalarda hatalı endikasyon sonucu çekim tercih edilebilmektedir. Dolayısıyla gereksiz diş kayıpları beraberinde maddi ve manevi yükler getirmektedir.

\section{SONUÇ}

kırık diş sendromundan şüphe- lenilen dişin detaylı periodontal ve endodontik muayenesi yapılmalıdır. Teşhis için literatürde tarif edilen metodlara uyulmalı ve ayırıcı tanıda değerlen- dirilecek faktörler dikkate alınmalıdır. Ayrıca kırık hattının KIBT ile izlenmesini, bu olguda görüldüğü gibi teşhis ve tedavi planlamasında faydalı olabilir. Etkilenen dişin prognozunun belirlenmesinin ardından tedavide öncelikle konservatif yaklaşımlar uygulan- malıdır. Etyolojide rol oynayan stres, anksiyete ve bruksizm gibi faktörler de ayrıca değerlendirilmeli ve gerekiyorsa tıbbi konsültasyon yapılm

alıdır.

\section{KAYNAKLAR}

1. Cameron CE. Cracked-Tooth Syndrome. J Am Dent Assoc 1964;68:405-11.

2. Geurtsen W, Schwarze T, Gunay H. Diagnosis, therapy, and prevention of the cracked tooth syndrome. Quintessence Int 2003;34:409-17.

3. Sümbüllü MA, Çakur B, Çağlayan F. Prevalence of Pituitary Calcifications Using Cone Beam Computed Tomography In Turkish Subpopulation. Atatürk Üniv Diş Hek Fak Derg 2013;21:289-92.

4. De Vos W, Casselman J, Swennen GR. Cone-beam computerized tomography (CBCT) imaging of the oral and maxillofacial region: a systematic review of the literature. Int J Oral Maxillofac Surg 2009;38:609-25.

5. Lynch CD, McConnell RJ. The cracked tooth syndrome. J Can Dent Assoc 2002;68:470-5.

6. Batalha-Silva $S$, Gondo $R$, Stolf $S$, Baratieri $L$. Cracked tooth syndrome in an unrestored maxillary premolar: a case report. Oper Dent 2014;39:4608.

7. Banerji S, Mehta SB, Millar BJ. Cracked tooth syndrome. Part 1: aetiology and diagnosis. Br Dent J 2010;208:459-63.

8. Greven M. TMD, bruxism, and occlusion. Am J Orthod Dentofacial Orthop 2011;139:424-5.

9. Friedman J, Marcus MI. Transillumination of the oral cavity with use of fiber optics. J Am Dent Assoc 1970;80:801-9.

10. Udoye $\mathrm{CI}$, Jafarzadeh $\mathrm{H}$. Cracked tooth syndrome: characteristics and distribution among adults in a Nigerian teaching hospital. J Endod 2009;35:3346.

11. Kalyan Chakravarthy PV, Telang LA, Nerali J, Telang A. Cracked tooth: a report of two cases and role of cone beam computed tomography in diagnosis. Case Rep Dent 2012;1:1-6.

12. Scarfe WC, Farman AG, Sukovic P. Clinical applications of cone-beam computed tomography in dental practice. J Can Dent Assoc 2006;72:7580.

13. Lee CY, Koval TM, Suzuki JB. Low Dose Radiation Risks of $\mathrm{CT}$ and $\mathrm{CBCT}$ : Reducing the Fear and Controversy. ] Oral Implantol 2014; [Basım Aşamasında]. 
14. Loubele $M$, Bogaerts $R$, Van Dijck $E$, Pauwels $R$ Vanheusden S, Suetens P, Marchal G, Sanderink G, Jacobs $\mathrm{R}$. Comparison between effective radiation dose of CBCT and MSCT scanners for dentomaxillofacial applications. Eur J Radiol 2009;71:461-8.

15. Mah JK, Danforth RA, Bumann A, Hatcher D. Radiation absorbed in maxillofacial imaging with a new dental computed tomography device. Oral Surg Oral Med Oral Pathol Oral Radiol Endod 2003;96:508-13.

16. Seltzer S, Boston D. Hypersensitivity and pain induced by operative procedures and the "cracked tooth" syndrome. Gen Dent 1997;45:148-59.

17. Dowell P, Addy M. Dentine hypersensitivity--a review. Aetiology, symptoms and theories of pain production. J Clin Periodontol 1983;10:341-50.

18. Fukumoto $Y$, Horibe $M$, Inagaki $Y$, Oishi $K$, Tamaki $\mathrm{N}$, Ito $\mathrm{HO}$, Nagata $\mathrm{T}$. Association of gingival recession and other factors with the presence of dentin hypersensitivity. Odontology 2014;102:429.

19. Ünal M, Tuğut F, Demir H. Travmatik Komplike Kuron Kırığı ve Lateral Lüksasyon Tedavisinin Üç Yıllık Takibi: Olgu Raporu. Atatürk Üniv Diş Hek Fak Derg 2013;23:380-4.

20. Üstün Y, Dinçer AN, Aslan T, Sağsen B. Bir Komplike Kron-Kök Kırığının Koruyucu Restorasyonu: Vaka Raporu. Atatürk Üniv Diş Hek Fak Derg 2013;23:235-8.

21. Banerji S, Mehta SB, Millar BJ. Cracked tooth syndrome. Part 2: restorative options for the management of cracked tooth syndrome. $\mathrm{Br}$ Dent J 2010;208:503-14.

22. Walton RE, Leonard LA. Cracked tooth: an etiology for "idiopathic" internal resorption? J Endod 1986;12:167-9.

23. Abou-Rass M. Crack lines: the precursors of tooth fractures-their diagnosis and treatment. Quintessence Int Dent Dig 1983;14:437-47.

24. Lobbezoo F, Naeije M. Bruxism is mainly regulated centrally, not peripherally. J Oral Rehabil 2001;28:1085-91.

25. Abe Y, Suganuma T, Ishii M, Yamamoto G, Gunji T, Clark GT, Tachikawa T, Kiuchi Y, Igarashi Y, Baba K. Association of genetic, psychological and behavioral factors with sleep bruxism in a Japanese population. J Sleep Res 2012;21:289-96.
26. Clark GT, Ram S. Four oral motor disorders: bruxism, dystonia, dyskinesia and drug-induced dystonic extrapyramidal reactions. Dent Clin North Am 2007;51:225-43.

27. Huynh N, Manzini C, Rompre PH, Lavigne GJ. Weighing the potential effectiveness of various treatments for sleep bruxism. J Can Dent Assoc 2007;73:727-30.

28. Johansson A, Omar R, Carlsson GE. Bruxism and prosthetic treatment: a critical review. J Prosthodont Res 2011;55:127-36.

29. Fernandes G, Franco AL, Siqueira JT, Goncalves DA, Camparis CM. Sleep bruxism increases the risk for painful temporomandibular disorder, depression and non-specific physical symptoms. J Oral Rehabil 2012;39:538-44.

30. Liebenberg $\mathrm{WH}$. Use of resin-bonded partial coverage ceramic restorations to treat incomplete fractures in posterior teeth: a clinical report. Quintessence Int 1996;27:739-47.

31. Bearn DR, Saunders EM, Saunders WP. The bonded amalgam restoration--a review of the literature and report of its use in the treatment of four cases of cracked-tooth syndrome. Quintessence Int 1994;25:321-6.

32. Banerji S, Mehta S, Kamran T, Kalakonda M, Millar B. A multi-centred clinical audit to describe the efficacy of direct supra-coronal splinting-A minimally invasive approach to the management of cracked tooth syndrome. J Dent 2014;42:862-71.

33. Rechenberg DK, Kruse A, Gratz KW, Attin T, Lubbers HT. Chronic orofacial pain (OFP) of different origin. A case report. Schweiz Monatsschr Zahnmed 2011;121:839-48.

34. Çağırankaya L, Erbudak H, Akçiçek G. Çatlak Diş Sendromu. Hac Dis Hek Fak Derg 2008;32:25-9.

\section{Yazışma Adresi}

Yrd. Doç. Dr. Cüneyt Asım ARAL

Şifa Üniversitesi, Diş Hekimliği Fakültesi, Periodontoloji Anabilim Dalı.

Mansuroğlu Mahallesi, 293/1 sokak, No 2, Bayraklı, İzmir.

Tlf : 02323080000 / 4358

E-posta: cuneytasimaral@gmail.com 